\title{
Efficacy of Copper Charged Water against Candida albicans
}

\author{
Rinky Mudiar $^{1 *}$, Ashok Bhagawat ${ }^{2}$ and Varsha Kelkar ${ }^{2}$
}

${ }^{1}$ Department of Biotechnology, Mumbai University, Maharashtra

${ }^{2}$ Department of Biotechnology, N. B. Mehta Science College, Bordi, Maharashtra

\begin{abstract}
Copper has been proved to be an effective antimicrobial agent with added advantage of being harmless to human at low concentration. This research has been done to assess the affectivity of copper along with some other metals, on an opportunistic pathogen Candida albicans. Copper was found to be the most potent of all. Metallic copper was then compared with copper charged water for its action on the same fungus. Along with this brilliant metal, its water also has antifungal action even better than a standard antifungal drug, fluconazole, at its MIC. Upon introduced in media, copper charged water shows changes in Candida growth pattern.
\end{abstract}

Keywords: Copper charged water; Conductivity, Candida albicans NCIM 3471; Time point killing assay; Atomic emission spectroscopy; Growth kinetics

\section{Introduction}

Copper was the first element to be discovered in metallurgy. Copper and its alloys, specifically brass and bronze were used in ancient India for making statues, utensils, ornaments, coins etc. In India ${ }_{2}$ copper was used to sterilize drinking water in 2600 B.C. and 2200 B.C. It is still used in many households for storing water.

Today copper is used as a water purifier, algaecide, fungicide, nematocide, and molluscicide and as an anti-bacterial and antifouling agent. Copper also displays potent anti-viral activity. Copper is considered safe to humans, as demonstrated by the widespread and prolonged use of copper intrauterine devices (IUDs) by women [1-3]. In contrast to the low sensitivity of human tissue (skin or other) to copper, microorganisms are extremely susceptible to copper. Studies have shown that copper can destroy orinhibit the growth of various bacterial strains. Antimicrobial copper, brass and bronze surfaces kill greater than $99.9 \%$ of bacteria within 2 hours of exposure [4]. Alloys with higher copper content kill organisms faster. It also boosts the immune system and prevents excess energy from being expended fighting off the infections.

Ayurveda recommend storing of water in copper vessels. When water is stored in a copper vessel, the copper gently leaches into the water and lends it all its positive properties. Drinking water stored in a copper vessel is beneficial to our health. According to Ayurveda, water stored in a copper vessel has the ability to balance all the three doshas in our body, (vata, kapha and pitta) and it does so by positively charging the water. The water stored in a copper vessel is known as 'tamarajal' and is supposed to be consumed after storing the water in a copper vessel for at least eight hours. Copper is an essential nutrient for humans as well as bacteria but, in high doses, copper ions can cause a series of negative events in bacterial cells. Copper's rate of microbial inactivation can be affected by temperature, copper concentration and the type of microorganism with which it is in contact. The mechanisms of antimicrobial action by copper and its alloys, including brass, is a subject of intense and on-going investigation.

Today, the antimicrobial uses of copper have been expanded to include fungicides, pesticides, antimicrobial medicines, oral hygiene products, hygienic medical devices etc. The fungal infections are not usually dangerous, although it can cause discomfort, may be resistant to treatment, and may spread to other parts of the body or other people. Affected feet can also become secondarily infected by bacteria. Opportunistic pathogens of human are the most common cause of infectious disease-related deaths in the United States [5]. They are the causes of variety of invasive or systemic fungal infections in immunocompromised or immunosuppressed individuals. Pathogens like, Candida, Fusarium, Trichosporon, and Malassezia species are emerging as important nosocomial pathogens.

Approximately $90 \%$ of human fungal infections are caused by Aspergillus, Candida, Cladosporium, Epidermophyton, Microsporum and Trichophyton species. These have become one of leading cause of death among patients due to greater use of broad spectrum antibiotics, immunosuppressive agents, and intensive care of low birth weight infants, organ transplantation and the acquired immunodeficiency syndrome (AIDS) epidemic. The situation is alarming in developing as well as developed countries like India, due to indiscriminate use of antibiotics. For instance, $33 \%$ of late-stage AIDS patients in one study had drug-resistant strains of Candida albicans in their oral cavities [6]. Hence, infection with this fungus is a major problem among immunecompromised patients (such as AIDS patients). For years, practices are being carried out to fight against these pathogens. Use of antimicrobial drugs such as broad spectrum antibiotics, herbal formulations, Ayurvedic medications such as decoctions; Bhashma, etc. are amongst them.

\section{Currently used antifungal agents}

There are many antifungals used currently, like Amphotericin B, Fluconazole, Itraconazole,Caspofungin etc. But these antifungal antibiotics are becoming ineffective leading to resistant strain development and various other drawbacks in terms of, for example, toxicity, drug-drug interactions and high cost [7]. Apart from sideeffects like liver damage or affecting oestrogen levels, many antifungal

*Corresponding author: Rinky Mudiar, Department of Biotechnology, Mumba University, Maharashtra, India, Tel: 02528254357; E-mail: rinky.mudiar@gmail.com

Received April 12, 2016; Accepted April 27, 2016; Published May 03, 2016

Citation: Mudiar R, Bhagawat A, Kelkar V (2016) Efficacy of Copper Charged Water against Candida albicans. J Food Process Technol 7: 583. doi:10.4172/21577110.1000583

Copyright: @ 2016 Mudiar R, et al. This is an open-access article distributed under the terms of the Creative Commons Attribution License, which permits unrestricted use, distribution, and reproduction in any medium, provided the original author and source are credited. 
medicines can cause allergic reactions in people. The scientific literature cites that copper kills microorganisms by multiple pathways rather than by acting in a specific way on one receptor. Hence, traditionally used copper charged water can be an interesting option to be analysed against pathogenic fungi. As copper is a natural mineral required by our body, it will also help in avoiding the adverse effects of already used antifungal drugs.

\section{Materials and Methods}

\section{Sample preparation and analysis}

A copper vessel of $99 \%$ purity was bought from a local market of Guwahati, Assam. Sterile demineralized water of known volume was kept in the cleaned vessel for $24 \mathrm{hrs}$ and aliquots were taken out at regular intervals for analysis. Surface to volume ratio of the vessel was calculated for the vessel. Conductivity and $\mathrm{pH}$ of the copper charged water were measured after $24 \mathrm{hrs}$. The aliquots were subjected to analysis by Inductively Coupled Plasma Atomic Emission Spectroscopy (ICP-AES), IIT Bombay, for the evaluation of copper elution rate from the vessel.

\section{Micro-organism and culture conditions}

Candida albicans NCIM 3471 (ATCC 10231) culture was purchased from NCIM, Pune. The strain was grown on potato dextrose agar media and incubated at $35^{\circ} \mathrm{C}$ for $48 \mathrm{~h}$ before use.

\section{Media and chemicals}

Potato dextrose agar (PDA) and broth (PDB) were bought from HiMedia. Standard fluconazole (ZOKON-50) $50 \mathrm{mg}$ tablets were used in the experiment.

\section{Effect of metals}

Candida suspension was prepared using sterile distilled water from a $48 \mathrm{hr}$ old culture. Equal volumes of the suspension containing $1.5 \times$ $10^{4}$ cells $/ \mathrm{ml}$ were kept in sterilized vessels of steel, aluminium, iron, brass and copper. Sterilized glass conical flask was used as control. All of them were incubated at room temperature (RT) for $24 \mathrm{hrs.} 100 \mu \mathrm{l}$ of each suspension was evenly spread onto sterile PDA plate, incubated for at RT for $48 \mathrm{hrs}$. CFU/ml was calculated and affectivity was checked.

\section{Time-point killing assay}

$1.5 \times 10^{4} \mathrm{cells} / \mathrm{ml}$ Candida culture was inoculated in copper charged water, copper vessel, fluconazole (32 ppm) and in Phosphate Buffered Saline (PBS). $100 \mu \mathrm{l}$ aliquots from each were plated onto sterile PDA at $0 \mathrm{~min}, 60 \mathrm{~min}, 120 \mathrm{~min}, 180 \mathrm{~min}$ and $24 \mathrm{hr}$. after incubation for $48 \mathrm{hr}$ at $\mathrm{RT}$, the $\mathrm{CFU} / \mathrm{ml}$ was calculated.

\section{Growth kinetics}

Growth curve was studied by inoculating $1 \times 10^{4}$ cells $/ \mathrm{ml}$ in sterile PDB prepared in distilled water and copper charged water respectively. The flasks were incubated at RT on a shaker at $120 \mathrm{rpm}$ and absorbance was measured at $600 \mathrm{~nm}$ at regular intervals for $48 \mathrm{hr}$. the experiment was performed at replicates and average readings were plotted to obtain the growth curve.

\section{Results}

\section{Copper charged water}

For the vessel, surface to volume ratio was measured and found to be approximately 1:1. Copper elution rate for the aliquots using ICP-
AES is shown graphically in Figure 1 . The water kept for $24 \mathrm{hr}$ in the vessel was found to be containing approximately $1 \mathrm{ppm}$ of copper ions. $\mathrm{pH}$ of this sample was found to slightly decreased from $\mathrm{pH}-7.3$ to $\mathrm{pH}$ 7.1. On the other hand conductivity increased from $39 \mathrm{uS} / \mathrm{cm}$ to 40.7 $\mathrm{uS} / \mathrm{cm}$.

\section{Effect of metals}

After exposing the Candida culture to different metallic surfaces for $24 \mathrm{hr}$, copper was found to be the most effective in killing the same, followed by brass, iron, aluminium and steel (Table 1).

\section{Time-point killing assay}

The average result of the replicates for this assay after each time interval is given in Table 2. Copper vessel is found to be showing the most potent anti-candida effect followed by copper charged water and then by fluconazole at its Minimum Inhibitory Concentration.

\section{Growth kinetics}

Growth curve for both media obtained by plotting Time in hour on $\mathrm{X}$-axis Versus Absorbance at $600 \mathrm{~nm}$ on $\mathrm{Y}$-axis is shown in Figure 2. Candida grown in media containing copper ions shows an extended lag phase compared to the control. Also the cell density remains less even when the culture entered stationary phase. Copper ions are hampering normal growth of Candida compared to the control media.

\section{Discussions}

The experiment supports the use of copper vessels as well as Tamarajal (copper charged water) as an antifungal agent. The dissolution of copper in the form of its ion gradually increases with time. We can observe the slight metallic sheen develops on the surface of water. The $\mathrm{pH}$ decreases slightly as the positively charged ions increases and hence the conductivity also increased slightly. Though intake of $1 \mathrm{ppm}$ copper charged water is not harmful for human, it has power to kill Candida.

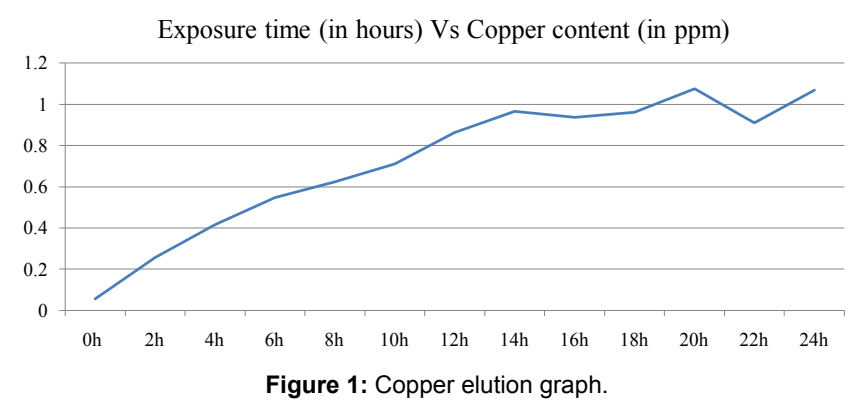

\begin{tabular}{|c|c|c|c|c|c|c|}
\hline Metals & Control & Steel & Aluminium & Iron & Brass & Copper \\
\hline $\mathrm{CFU} / \mathrm{ml}$ & 992 & 934 & 828 & 654 & 370 & 120 \\
\hline
\end{tabular}

Table 1: Effect of metals on Candida albicans.

\begin{tabular}{|c|c|c|c|c|}
\hline Time & PBS (control) & $\begin{array}{c}\text { Fluconazole } \\
\text { (32 ppm) }\end{array}$ & $\begin{array}{c}\text { Copper charged } \\
\text { water (1 ppm) }\end{array}$ & Copper vessel \\
\hline $0 \mathrm{~min}$ & 1337 & 1289 & 1297 & 1203 \\
\hline $60 \mathrm{~min}$ & 1321 & 1285 & 1245 & 158 \\
\hline $120 \mathrm{~min}$ & 1237 & 1248 & 1154 & 150 \\
\hline $180 \mathrm{~min}$ & 1219 & 1215 & 1110 & 8 \\
\hline $24 \mathrm{hrs}$ & 1023 & 798 & 234 & 3 \\
\hline
\end{tabular}




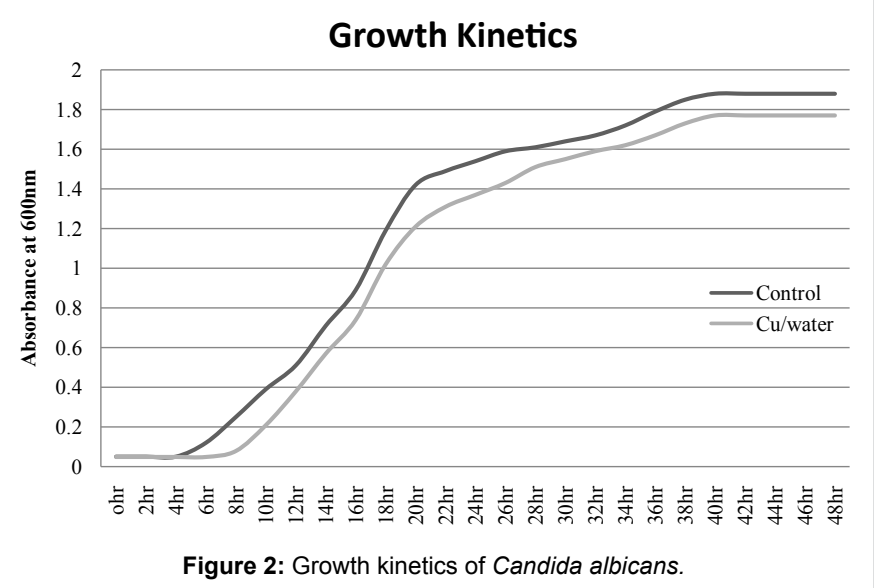

Copper metal is most effective in killing Candida while other metals did not show much effect on the same, although brass shows some, only because it is an alloy of copper again.

In order to find out the time required to kill Candida, time point killing assay was performed. Here, culture suspension was made in demineralized water to eliminate any reaction between chloride ion in saline and copper ions. Fluconazole was also used to compare its efficacy with metallic copper and copper charged water. As the MIC of fluconazole for Candida albicans NCIM 3471 was found to be reported as $32 \mathrm{ppm}$, this concentration was used in this assay for comparison. Unlike bacteria which are mostly killed within $2 \mathrm{hrs}$ of exposure to copper, Candida needs more exposure time for the same.

The copper surface of the vessel was effective within $3 \mathrm{hrs}$ on Candida whereas copper charged water took $24 \mathrm{hrs}$ to be effective. This is because metallic surface exposure by contact is much more toxic than its ions present in water. However, compared to fluconazole which is used as a standard antifungal drug, copper charged water was found to be more potent. The enhanced time of exposure for its activity may be due to the complex organization of Candida than bacteria and its ability to uptake copper ions in the cell during initial period of exposure. When growth of Candida in its media prepared in copper charged water was studied, the graph indicated an extended lag phase from $4 \mathrm{hrs}$ (control) to $6 \mathrm{hr}$ (copper-charged media). This might be due to harsh environment provided by the copper ions in the media. Although the culture gains its exponential phase due to the nutrient availability, its cell density remains less than the control media even in stationary phase.

\section{Future perspectives}

Investigations are being carried out on the effect of copper and its water on other fungus as well as its mechanism of action. It can be a boon for developing potent but harmless drugs for the treatment of fungal diseases.

\section{Acknowledgement}

Authors would like to thank SAIF, IIT, Bombay for the facility of ICP-AES. They are grateful to the Principal, N. B. Mehta Science College, Bordi for allowing the use of laboratory. Sincere thanks to Mr. Sandip Vadaliya for his support.

\section{References}

1. Sagripanti JL, Routson LB, Lytle CD (2001) Infection Control (2ndedn). International Copper Research Association.

2. Yamamoto N, Haller W, Hiatt CW (1964) Mechanism of inactivation of bacteriophages by metals. Biochim Biophys Acta 91: 257-261.

3. Bilian X (2002) Intrauterine devices. Best Pract Res Clin Obstet Gynaecol 16 : 155-168.

4. (2010) Antimicrobial Copper FAQs, CDA Publication.

5. Odds FC (2000) Resistance of yeasts to azole-derivative antifungal. J Antimicrob Chemother 31: 463-471.

6. White (2002) Resistance mechanisms in clinical isolates of Candida albicans. Antimicrob Agents Chemother 46: 61704-61713.

7. Runyoro (2006) Screening of Tanzanian medicinal plants for anti-Candida activity. BMC Complement Altern Med 6: 11-20. 